\author{
Marquette University \\ e-Publications@Marquette
}

Electrical and Computer Engineering Faculty

Research and Publications

Electrical and Computer Engineering,

Department of

\title{
Conceptual Design of Sleeve Rotor Synchronous Reluctance Motor for Traction Applications
}

\author{
Patel B. Reddy \\ General Electric Global Research \\ Kevin Grace \\ General Electric Global Research \\ Ayman M. El-Refaie \\ Marquette University, ayman.el-refaie@marquette.edu
}

Follow this and additional works at: https://epublications.marquette.edu/electric_fac

Part of the Computer Engineering Commons, and the Electrical and Computer Engineering Commons

\section{Recommended Citation}

Reddy, Patel B.; Grace, Kevin; and El-Refaie, Ayman M., "Conceptual Design of Sleeve Rotor Synchronous Reluctance Motor for Traction Applications" (2016). Electrical and Computer Engineering Faculty Research and Publications. 682.

https://epublications.marquette.edu/electric_fac/682 
Marquette University

e-Publications@Marquette

\section{Electrical and Computer Engineering Faculty Research and Publications/College of Engineering}

This paper is NOT THE PUBLISHED VERSION.

Access the published version via the link in the citation below.

IET Electric Power Applications, Vol. 10, No. 5 (May 2016): 368-374. DOI. This article is @ Institution of Engineering and Technology and permission has been granted for this version to appear in $\underline{\mathrm{e}-}$ Publications@Marquette. Institution of Engineering and Technology does not grant permission for this article to be further copied/distributed or hosted elsewhere without express permission from Institution of Engineering and Technology.

\section{Conceptual Design of Sleeve Rotor Synchronous Reluctance Motor for Traction Applications}

\section{Patel Bhageerath Reddy}

Electric Machines Laboratory, General Electric Global Research, Niskayuna, USA

Kevin Grace

Electric Machines Laboratory, General Electric Global Research, Niskayuna, USA

Ayman El-Refaie

Electric Machines Laboratory, General Electric Global Research, Niskayuna, USA

\footnotetext{
Abstract

Synchronous reluctance machines are very appealing for high speed traction motor design due to their robustness, simple structure, absence of magnets, and simple control. The absence of magnets means that synchronous reluctance (SynRel) machines are not susceptible to price variability and sustainability of rare-earth materials. Moreover, there are no concerns about demagnetisation or uncontrolled generation mode. However, the challenge of achieving a good constant power to speed
} 
ratio is dependent on the mechanical aspects of the design. Conventional SynRel designs perform poorly compared with the permanent magnet machines due to the presence of bridges and/or centre posts in absence of the magnets to help saturate these regions. In this case, the challenge of rotor mechanical retention is addressed with the help of a sleeve on the rotor to reduce the need for bridges and/or centre posts. Design optimisation including the mechanical aspects of the sleeve is presented in this study. The final design with a sleeve will be shown to be superior to a conventional design in terms of power density, rotor losses, saliency and torque ripple.

\section{Introduction}

While interior permanent magnet (IPM) machines have been the primary candidates for traction motors in light-duty hybrid/electric vehicles, the price and availability of magnets have been a cause of concern. Typically these motors use neodymium iron boron (NdFeB) permanent magnets, which contain both light rare earth materials as neodymium as well as heavy rare-earth materials as dysprosium (Dy). One of the key risks in terms of using these rare-earth magnets is the significant fluctuation/increase in their prices over the past few years. Traction applications as well as wind generators that use large quantities of these magnets were the most affected by these fluctuations. There has been an ongoing global effort to try to reduce or eliminate the use of rare earth materials without sacrificing performance. As a part of elimination of rare-earth materials, conventional topologies such as induction, switched reluctance and synchronous reluctance (SynRel) are being considered as alternatives.

SynRel machines are particularly appealing due to their smooth and simple passive rotor structure, comparable power density to induction motors [1-6], low rotor losses and synchronous operation/simple control [7-9]. The key disadvantages of the SynRel machine are low power factor and typically limited constant power speed ratio (CPSR) [10]. This is mainly due to the presence of bridges and/or centre-posts, especially in high-speed machines.

In this paper, a SynRel design with a retaining sleeve will be presented. The key novelty in this design is that it eliminates the need for centre posts as well as being suitable for high-speed operation. This construction helps solve the issue of the leakage paths in the centre posts as well as reduces the torque ripple and rotor losses. The use of sleeves is not uncommon in surface permanent magnet machines.

This machine was designed to meet the FreedomCAR DOE 2020 specifications summarised in Fig. 1a as well as Table 1. The goal of this paper is to come up with a SynRel design targeting the same set of specifications. The paper will provide a detailed comparison between the various design iterations highlighting the key tradeoffs in terms of power density, efficiency, rotor losses, flux-weakening capability, mass and torque ripple.

Table 1. Summary of key FreedomCar 2020 advanced traction motor requirements

\begin{tabular}{|l|l|}
\hline Parameter/Metric & Value \\
\hline peak power @ 2800 r/min & $55 \mathrm{~kW}$ \\
\hline maximum speed & $14,000 \mathrm{r} / \mathrm{min}$ \\
\hline continuous power & $30 \mathrm{~kW}$ \\
\hline mass power density for total machine & $>1.6 \mathrm{~kW} / \mathrm{kg}$ \\
\hline
\end{tabular}




\begin{tabular}{|l|l|}
\hline vol. power density for total machine & $>5.67 \mathrm{~kW} / \mathrm{I}$ \\
\hline constant power speed ratio & $5: 1$ \\
\hline maximum phase current & $400 \mathrm{Arms}$ \\
\hline peak line-to-line back-emf @ 2800 r/min & $600 \mathrm{~V}$ \\
\hline efficiency at 20\% rated torque up to the max. speed & $>95 \%$ \\
\hline
\end{tabular}

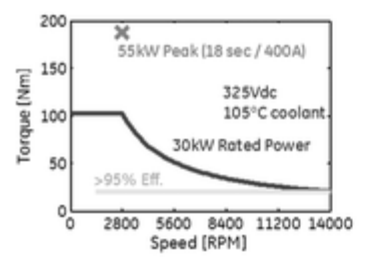

a
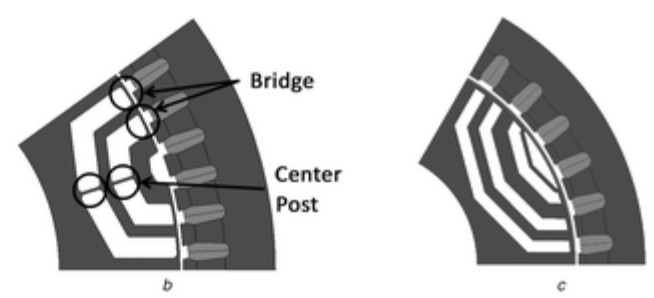

Fig. 1 Cross-section of a conventional synchronous rotor $a$ FreedomCar 2020 motor specified torque-speed curve $b$ Cross-section of a Conventional SynRel Design

$c$ Cross-section of a SynRel using a retaining sleeve on the rotor

The design presented in [11] used rare-earth permanent NdFeB magnets including Dy. This design was able to achieve a (CPSR) as well as high efficiencies. The effect of using various magnet types/grades in spoke IPM machines was also presented [1, 12-14].

\section{Proposed synchronous reluctance topology}

The SynRel rotor topology that will be investigated has a non-magnetic retaining sleeve on the outer periphery of the rotor. The sleeve can be made out of either carbon-fibre or high-strength conductive non-magnetic material such as Inconel. Use of carbon fibre is effective in reducing the rotor losses, but it has comparably lower thermal capability. On the other hand, conductive materials like Inconel can eliminate the thermal concern at the cost of higher sleeve losses. The cross-section of a conventional synchronous rotor is shown in Fig. $\mathbf{1 b}$, and the concept of having a retaining sleeve rotor is shown in Fig. 1c, where the sleeve is depicted by the grey region on the rotor.

For the purpose of electromagnetic analysis, both of the carbon fibre and Inconel sleeves can be modelled as air (adding to the effective air gap) of a certain thickness. However, in the final loss investigations, the Inconel sleeve can incur eddy current losses while the carbon fibre sleeve does not have any electromagnetic losses.

\section{Effect of air-gap radius on a SynRel}

It is understood that the sleeve thickness itself can be a function of air-gap radius/tip speed. At lower radii, the sleeve thickness is smaller, which benefits the reluctance, while at higher radii the sleeve thickness has to be increased to compensate for higher centrifugal forces. This has a counter-balance effect on the increased torque density at the higher radius. The effective air-gap thickness is equal to the sum of the sleeve thickness and the physical air-gap.

The design is optimised for torque density at peak power, as per the specs in Table 1. At the same time, the design also needs to provide maximum power at the top speed of $14,000 \mathrm{rpm}$ in order to meet the 
continuous power of $30 \mathrm{~kW}$, as mentioned in the previous section. All of these designs are compared in terms of the stack length, total active mass, copper mass, available power at top speed of 14,000 rpm, efficiency while delivering the continuous power of $30 \mathrm{~kW}$ at the corner point of 2800 and the top speed of $14,000 \mathrm{rpm}$. Based on this study, the final air-gap radius is chosen for the sleeve rotor design.

In the absence of full blown mechanical optimisation of the sleeve thickness, two different air-gap thickness functions are considered for the SynRel design to reflect the two choices of the sleeve material - (i) Carbon fibre (air-gap function 1), (ii) Inconel (air-gap function 2). From a mechanical perspective, the sleeve thickness can be different between the two materials due to the difference in tensile strengths. Each of these air-gap functions provide a relation between the effective air-gap in the machine as a function of the rotor outer radius. Since it was not possible to include a coupled optimisation of the electromagnetic and mechanical analysis, an air-gap function is seen as an effective way of including first order mechanical effects into the electromagnetic performance. With an assumption that a sleeve is not needed at lowest radius and the minimum air-gap thickness of $0.5 \mathrm{~mm}$ is needed, one of the air-gap thicknesses asymptote to a value of $0.5 \mathrm{~mm}$ at lower radii, while the other function asymptotes to $0.75 \mathrm{~mm}$. In addition each of the air-gap function has a quadratic relation with the air-gap thickness in accordance to the increase in the centrifugal force of the lamination. Two air-gap functions are used to include the possibility of two different sleeve materials i.e. Inconel and carbon fibre.

The chosen effective air-gap (sleeve + physical air-gap) functions are shown in Fig. 2a. These air-gap thickness functions capture a first order effect of the centrifugal forces showing sleeve thickness squared vs. rotor radius. Since the problem of mechanical retention is a complex one, these thickness functions do not account for the exact rotor shape and only represent a function to be used for electromagnetic optimisation. The design is optimised at each of the operating points for the torque density under the peak torque conditions. For the sake of simplification, the post and bridges are eliminated in the designs. The stator is a conventional 2-slot/pole/phase stator comprising of 60 slots, while the rotor has 10 poles. For the sake of comparison to a conventional SynRel rotor, the pole and slot number is fixed to 10 and 60, respectively. The masses and stack lengths of optimised designs are shown in Figs. $\mathbf{2 b}$ and c, respectively. Interestingly, the optimum seems to occur at two points i.e. 90 and $60 \mathrm{~mm}$. However on closer inspection, it is found the designs with rotor radius below $80 \mathrm{~mm}$ cannot achieve the continuous power of $30 \mathrm{~kW}$ at the top speed of $14,000 \mathrm{rpm}$. It is only the designs at 80,90 and $100 \mathrm{~mm}$, which are able to produce power close to $30 \mathrm{~kW}$ at top speed as shown in Fig. $2 \mathrm{~d}$. Designs with lower air-gap radii become quite long axially and are at a disadvantage to produce the necessary power at the top speed. 

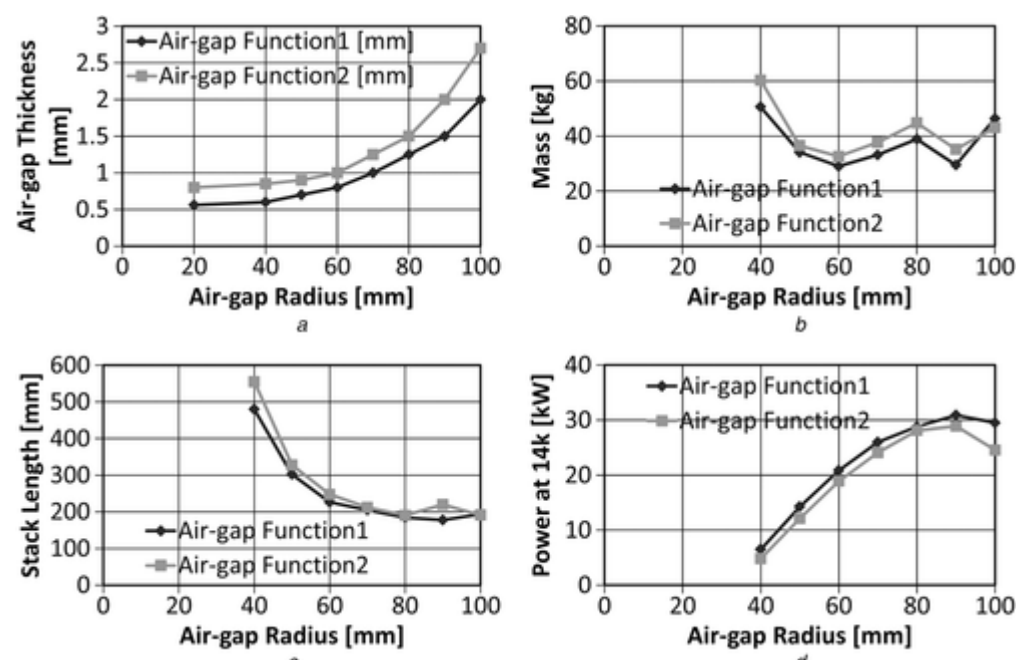

Fig. 2 Chosen effective air-gap (sleeve + physical air-gap) functions and masses and stack lengths of optimised designs

a Air-gap thickness functions against air-gap radius

$b$ Mass of optimised designs of the two air-gap

$c$ Stack length of optimised designs of the two air-gap functions

$d$ Power achievable at top speed by optimised designs of the two air-gap functions against air-gap radius

Total efficiency under the continuous power of $30 \mathrm{~kW}$ at top speed shown in Fig. 3a indicates that designs above 80 up to $100 \mathrm{~mm}$ have the best performance. The lower radii designs cannot produce the requisite $30 \mathrm{~kW}$ and hence the efficiency is better in designs beyond $80 \mathrm{~mm}$ due to the higher achievable power as shown in Fig. 2d. Based on the above analysis, it is understood that an air-gap radius of $90 \mathrm{~mm}$ is optimal for use with a sleeve. However, since this does not account for a complete mechanical analysis, the final optimisation is done at two rotor radii of 90 and $100 \mathrm{~mm}$. 

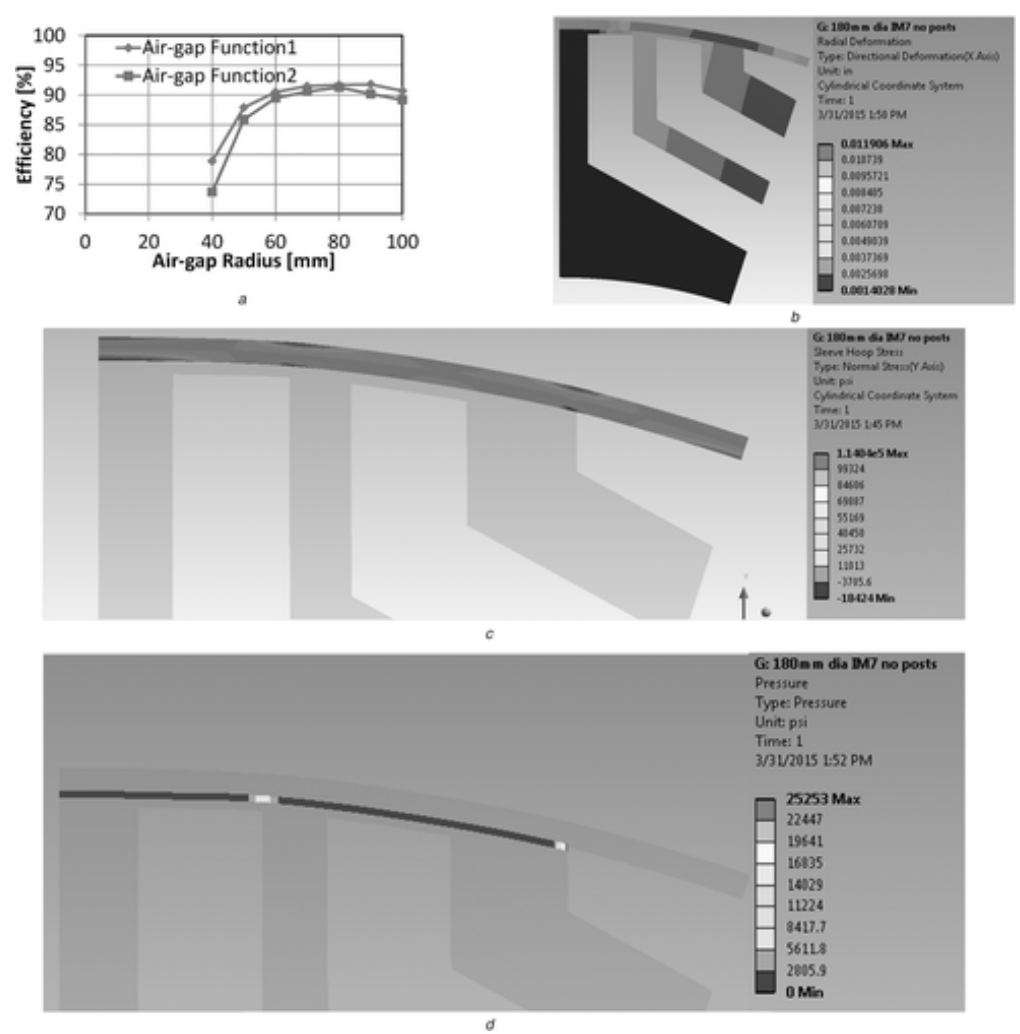

Fig. 3 Total efficiency under the continuous power of $30 \mathrm{~kW}$ at top speed

$a$ Efficiency at the maximum power achievable at top speed by optimised designs of the air-gap functions $b$ Deformation in the sleeve of the $100 \mathrm{~mm}$ sleeve design

$c$ Hoop Stress in the sleeve of the $100 \mathrm{~mm}$ sleeve design

$d$ Pressure contact of sleeve of the $100 \mathrm{~mm}$ sleeve design

\section{Mechanical design of sleeve rotor}

The use of a continuous circumferential sleeve for mechanical retention of rotor components has been used extensively in surface PM machines. There is an inherent downside of using a continuous sleeve that comes from increasing the air gap of the machine. The physical air gap can typically remain the same, but the electro-magnetic gap must increase due to the thickness of the sleeve on the rotor. The sleeve material is required to be of a non-magnetic material as to not interfere with the flux paths in the rotor. In addition, a monolithic magnetic material in the air gap would be subject to large eddy current losses. Inconel material has been used for rotor sleeves because it is non-magnetic and can be machined easily to a tight tolerance.

Another suitable material candidate is graphite fibre composite. It is non-magnetic and has a tensile strength many times that of steel or Inconel. To construct the composite sleeve, layers of graphite fibres are laid in the circumferential direction (hoop layers) with axial layers periodically in between to provide stiffness in the axial direction of the rotor. IM7 graphite fibre material with $90 \%$ hoop layers and $10 \%$ axial layers is used in this analysis. The layers are covered with a resin to bond them together and cured. The material properties for the IM7 90/10 are orthotropic proportional to the ratio of hoop layers to axial layers. 
An axisymmetric analysis of half of one rotor pole was used to determine the required thickness of the sleeve for each of component designs. The stress analysis assumes the rotor laminations are keyed on to the rotor and torque transmission happens through a key. The rotor lamination for the 10-pole, 2layer SynRel rotor design is allowed to have $0.5 \mathrm{~mm}$ thick bridges to preserve the integrity of the lamination and hence allow for easier manufacturability. In addition, since the largest diameter rotor design is $200 \mathrm{~mm}$, the sleeve thicknesses are varied from 0.5 to $2 \mathrm{~mm}$, while the interference fit on the sleeve is varied from 0 to 10 mil at the contact. It is seen that the Inconel material is not stiff enough to constrain the radial growth of the lamination within the thickness range limited by $2 \mathrm{~mm}$. The analysis essentially eliminated the use of Inconel sleeve since a thicker Inconel sleeve will lead to a significant hit on the EM performance.

Similar analysis performed with graphite fibre composite sleeve has led to a sleeve thickness of $1 \mathrm{~mm}$ sleeve thickness being stiff enough to retain the lamination growth without exceeding the allowable stress of the IM7 material. One of the primary concerns is the deformation of the sleeve into the airgap and it is seen in Fig. $\mathbf{3 b}$ that the maximum deformation of the sleeve into the air-gap is limited to 12 mils, essentially $33 \%$ of the air-gap. Fig. 3c shows the hoop stress within the carbon fibre sleeve is limited to $200 \mathrm{ksi}$ while the tensile strength of IM7 90/10 is about 8 times the max stress in the material, and hence the stress safety factor is very conservative. In addition the maximum deflection in the laminations is limited to 12 mils as well but occurring in the inner regions. However in addition to adhering to the stress limits of the graphite fibre, additional constraints were added in terms of the pressure limits at the interface between the rotor lamination and the sleeve. In other words, under rotation one of the constraints was that the graphite fibre does not loose surface contact with the rotor lamination, as well as have a pressure point beyond the yield strength of the carbon fibre. This is seen in Fig. $\mathbf{3 d}$, where the pressure at most of the interface is within the limits of $200 \mathrm{ksi}$, with a single stress concentrator reaching this limit.

\section{Performance of sleeve rotors}

On the basis of the mechanical analysis, the final sleeve thickness is 1.0 and $2.0 \mathrm{~mm}$ for the carbon fibre and Inconel materials, respectively. An optimisation of the design is done around the respective sleeves with the primary objective of torque density. Since the previous optimisation runs indicated that an optimal design exists at around a rotor radius of $90 \mathrm{~mm}$, optimisation is done at both 90 and $100 \mathrm{~mm}$ air-gap radii. Both the designs use a carbon fibre sleeve thickness of $1 \mathrm{~mm}$, and with the airgap being $0.7 \mathrm{~mm}$, the total effective air-gap in either of the designs is equal to $1.7 \mathrm{~mm}$. The final design cross-section of the design for 100 mm air-gap radii are shown in Fig. 4. 


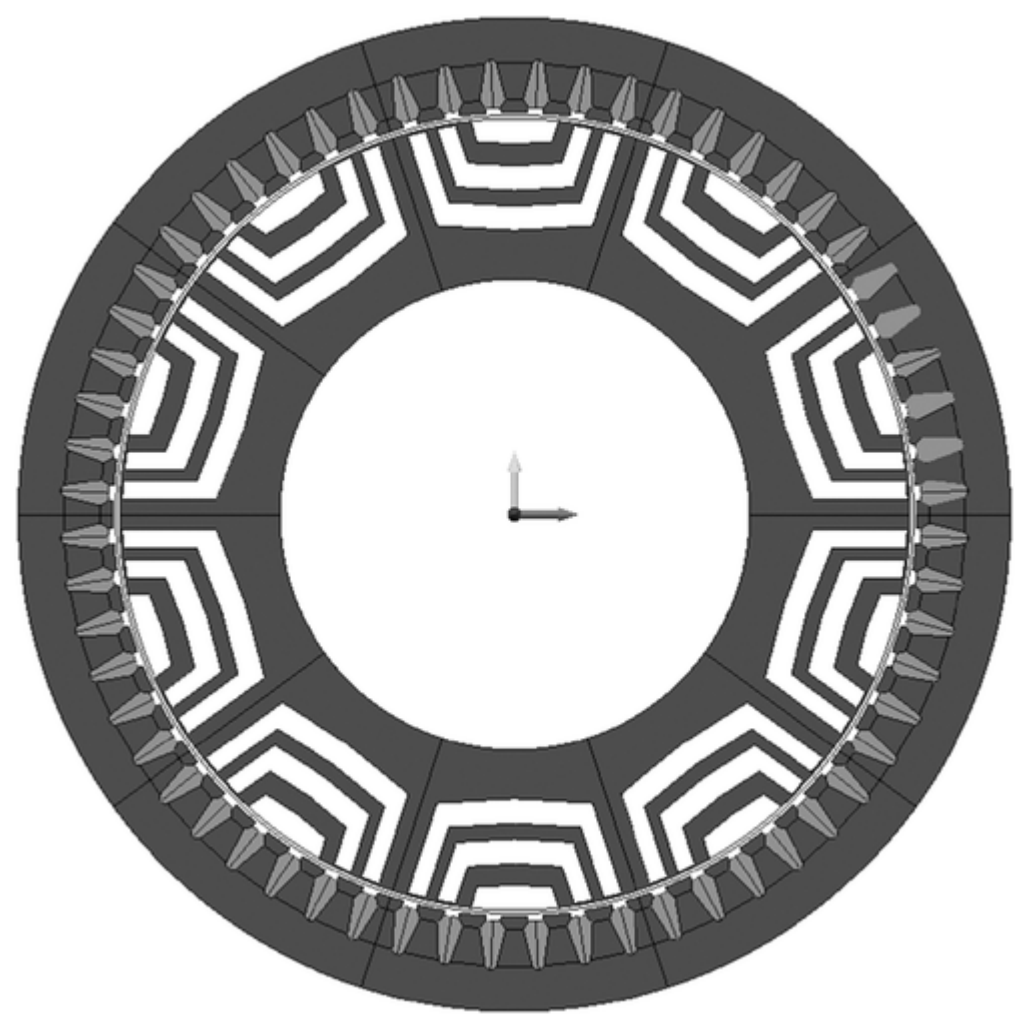

Fig. 4 SynRel Design with air-gap radius as $100 \mathrm{~mm}$, showing the grey carbon fibre sleeve

The performance of the final sleeve designs is shown in Table 2. Interestingly, even though the designs are different in terms of the air-gap radii and the stack length, the designs are quite similar in terms of their final mass values as well as performances in terms of power density, high speed power and efficiencies. The overall active mass of the designs are 35.8 and $35.4 \mathrm{~kg}$ for the $90 \mathrm{~mm}$ and the $100 \mathrm{~mm}$ designs, respectively, and both of the designs are quite similar in terms of the power density, reaching values of 1.69 and $1.71 \mathrm{~kW} / \mathrm{kg}$ respectively. Both of the designs end up having similar copper mass in the end regions, while the difference in the copper mass comes in due to the difference in lengths. This leads to the $100 \mathrm{~mm}$ design having a significantly lower copper mass of $3.8 \mathrm{~kg}$, compared with the $5.4 \mathrm{~kg}$ of the $90 \mathrm{~mm}$ design. Both designs do not contain magnets and the active material cost is lower than that of a permanent magnet motor.

Table 2. Performance of sleeve designs

\begin{tabular}{|l|l|l|}
\hline Item & $\mathbf{9 0} \mathbf{~ m m}$ & $\mathbf{1 0 0 ~} \mathbf{~ m m}$ \\
\hline stack Length [mm] & 247.5 & 165.75 \\
\hline mass w/o shaft $[\mathrm{kg}]$ & $35.8 \mathrm{~kg}$ & $35.4 \mathrm{~kg}$ \\
\hline total copper mass $[\mathrm{kg}]$ & $5.45 \mathrm{~kg}$ & $3.83 \mathrm{~kg}$ \\
\hline end turn copper mass [kg] & $1.78 \mathrm{~kg}$ & $1.61 \mathrm{~kg}$ \\
\hline stator OD [mm] & $222.7 \mathrm{~mm}$ & $249.1 \mathrm{~mm}$ \\
\hline air-gap diameter [mm] & $180 \mathrm{~mm}$ & $200 \mathrm{~mm}$ \\
\hline rotor ID [mm] & $120.5 \mathrm{~mm}$ & $117.9 \mathrm{~mm}$ \\
\hline physical air-gap $[\mathrm{mm}]$ & $1.7 \mathrm{~mm}$ & $1.7 \mathrm{~mm}$ \\
\hline power density $[\mathrm{kW} / \mathrm{kg}]$ & 1.69 & 1.71 \\
\hline peak power at TCP [kW] & 60.5 & 60.4 \\
\hline
\end{tabular}




\begin{tabular}{|l|l|l|}
\hline saliency at peak power & 3.11 & 3.29 \\
\hline power at 14 $\mathrm{k}[\mathrm{kW}]$ & $29.4 \mathrm{~kW}$ & $28.2 \mathrm{~kW}$ \\
\hline efficiency at TCP [\%] & 85.4 & 85.5 \\
\hline efficiency at $14 \mathrm{k}[\%]$ & 90.2 & 91.4 \\
\hline
\end{tabular}

Since the design topologies are similar and the $100 \mathrm{~mm}$ design has a slight advantage in terms of mass, saliency and efficiency, the results from the $100 \mathrm{~mm}$ design are investigated in detail and are used for the final comparison to the conventional SynRel motor in the next section.

The $100 \mathrm{~mm}$ fares only slightly better in terms of the saliency at peak power as well as the top speed conditions. Under the peak power conditions, the motor is under saturation. The flux density variation with the electrical angle as well as the harmonics under the peak torque conditions are illustrated in Figs. 5a and $\mathbf{b}$. Clearly, except at the regions of the bridges and stator tooth base, most of the machine is quite unsaturated, especially the rotor $q$-axis path and along the stator yoke. Either of these sections sees a flux density of $1.5 \mathrm{~T}$, while the tooth and bridge regions reach the saturation flux density of $2.1 \mathrm{~T}$.

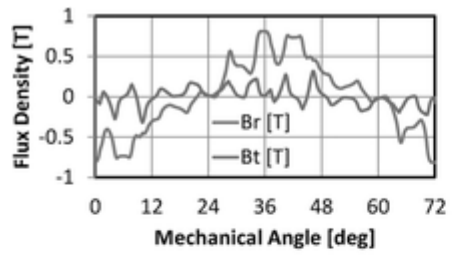

a

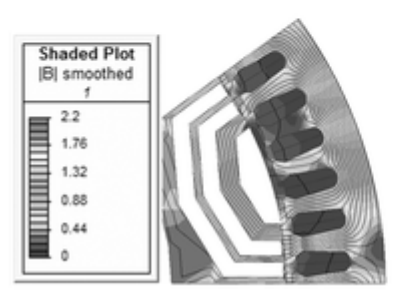

$c$
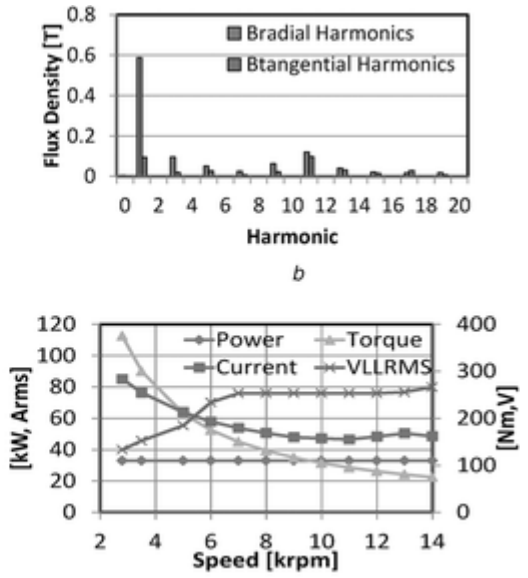

Fig. 5 Flux density variation with the electrical angle as well as the harmonics under the peak torque conditions a Air-gap Flux Density under the peak torque excitation of $400 \mathrm{Arms}, 50^{\circ}$ gamma in the $100 \mathrm{~mm}$ Carbon Fibre SynRel

$b$ Radial and Tangential Air-gap Flux Density Harmonics under the peak torque excitation in the Carbon Fibre SynRel

$c$ Peak Torque Excitation of 400 Arms, $50^{\circ}$ gamma in the $100 \mathrm{~mm}$ Carbon Fibre SynRel Design

$d$ Power, Current, Torque and Voltage under the rated conditions for the $100 \mathrm{~mm}$ Carbon Fibre SynRel Design

The air-gap flux density contours with the $100 \mathrm{~mm}$ design under the peak torque conditions (i.e. an excitation of $400 \mathrm{Arms}, 50^{\circ}$ gamma) are shown in Fig. 5c. The graph shows that both the radial and tangential flux densities contain significant harmonics, while the radial flux density almost resembles a saw-tooth waveform. Peak values of the Fourier harmonic components of the radial and tangential flux densities under the peak torque condition are shown in Fig. 5b. Clearly the peak radial flux density does not exceed $0.6 \mathrm{~T}$, which can be considered to be fairly low when compared with permanent magnet machines. The lower magnetic loading can have a direct impact on the size of the machine. In addition, the air-gap field is rich in harmonics, especially around the 11th harmonic, arising from the 
combination of the stator tooth and rotor tooth modulation. In other words, the stator excitation arising from six teeth is modulated by the five tooth stepped rotor permeance. The 11th harmonic is capable of causing rotor losses but not sleeve losses due to the non-conducting nature of the sleeve. The rated performance with regards to the power, torque, current and line voltage of the $100 \mathrm{~mm}$ design is shown in Fig. $\mathbf{5 d}$. It can be seen that the continuous current is quite high under the lower speed conditions, and quickly falls within the 200 Arms limit. On the other hand, the voltage across the machine reaches the limit of the six-step voltage at around a speed of $7000 \mathrm{rpm}$, indicating the machine voltage corner point.

\section{Comparison with conventional SynRel}

For the sake of comparison, a conventional SynRel motor (with magnetic bridges and posts) is designed with 10 poles and 2 layers. The sizing of the bridges and centre posts is based on mechanical analysis at $14,000 \mathrm{rpm}$. In order to simplify the optimisation of the conventional SynRel, the bridges and posts thicknesses were fixed at $0.63 \mathrm{~mm}$. The EM optimisation revealed that if a conventional SynRel motor is designed for peak power, it is unable to maintain the CPSR up to the top speed but only until a speed of $10,000 \mathrm{rpm}$. Above speeds of $12,000 \mathrm{rpm}$, the design begins losing power and drops to $29 \mathrm{~kW}$ at the top speed. As previously discussed, this is mainly due to the high leakage of the magnetic bridges and posts.

The comparison of the sleeve vs. conventional design is summarised in Table 3. As mentioned before, all of the designs are designed for similar peak output power at the corner point of $2800 \mathrm{rpm}$. However, since the sleeve designs are capable of the peak power of $60 \mathrm{~kW}$; they are designed for a $10 \%$ higher peak power, so as to make them conducive for future experimental work. On the other hand, the conventional SynRel design is only able to achieve a peak power of $56 \mathrm{~kW}$, while maintaining the continuous power up to $12,000 \mathrm{rpm}$. In spite of the higher peak power output, the sleeve design comes out $29 \%$ better in terms of power density than the conventional SynRel machine. One of the main reasons for better power density is that the sleeve allows an increase in air-gap radius, which is beneficial as discussed in the previous section.

Table 3. Performance of final designs

\begin{tabular}{|l|l|l|}
\hline & Sleeve SynRel & Conventional SynRel \\
\hline poles & 10 & 10 \\
\hline layers & 2 & 2 \\
\hline sleeve thickness [mm] & 1.0 & 0 \\
\hline EM air-gap [mm] & 1.7 & 0.7 \\
\hline stack length [mm] & 165.75 & 315 \\
\hline active mass [kg] & $35.4 \mathrm{~kg}$ & $42.7 \mathrm{~kg}$ \\
\hline stator OD [mm] & $249.1 \mathrm{~mm}$ & $201 \mathrm{~mm}$ \\
\hline air-gap diameter [mm] & $200 \mathrm{~mm}$ & $155 \mathrm{~mm}$ \\
\hline rotor ID [mm] & $117.9 \mathrm{~mm}$ & $99 \mathrm{~mm}$ \\
\hline physical air-gap [mm] & $1.7 \mathrm{~mm}$ & $0.7 \mathrm{~mm}$ \\
\hline power density [kW/kg] & 1.71 & 1.32 \\
\hline peak power at TCP [kW] & 60.4 & 56.3 \\
\hline saliency at peak power & 3.29 & 2.89 \\
\hline
\end{tabular}




\begin{tabular}{|l|l|l|}
\hline power at $14 \mathrm{k}[\mathrm{kW}]$ & $28.2 \mathrm{~kW}$ & $18.2 \mathrm{~kW}$ \\
\hline saliency at $14 \mathrm{k}$ & 3.03 & 2.034 \\
\hline efficiency at TCP [\%] & 85.5 & 85.1 \\
\hline efficiency at 14 $\mathrm{k}[\%]$ & 91.4 & 87.9 \\
\hline torque ripple at peak power [\%] & 9.5 & 72.8 \\
\hline
\end{tabular}

The rated output shaft power vs. speed for both motors is shown in Fig. 6a. The sleeve design is able to maintain a power above $30 \mathrm{~kW}$ over the entire speed range (i.e. from 2800 to 14,000 rpm), while the conventional SynRel design sees a more rapid reduction in the available rated power, especially beyond the speed of $10 \mathrm{k} \mathrm{rpm}$. The reason for the gradual reduction in the rated power vs. speed in the motors is understood by observing the saliency shown in Fig. $\mathbf{6 b}$. The saliency of the conventional SynRel design is well below 3, while the saliency in the sleeve design under the rated power conditions is close to 3. Higher saliency in the SynRel machine is beneficial because torque production arises solely from the reluctance torque. The bridges and the posts in the conventional SynRel machine are the primary paths of the leakage flux, which leads to the reduction in the saliency in this design. The sleeve design has bridges of lower thickness, which limits the limits the leakage flux and improves the saliency. Better saliency has an effect on the power at the lower speed as well as the corner point. The comparison of the voltage under rated conditions shown in Fig. $\mathbf{6 c}$ indicates that the conventional rotor is not capable of staying within the voltage limit beyond a speed of 10,000 rpm. Extensive parameter variation in terms of the turns/phase as well as geometry variation failed to yield a design which is capable of producing the required $30 \mathrm{~kW}$ power up to the top speed of $14,000 \mathrm{rpm}$.
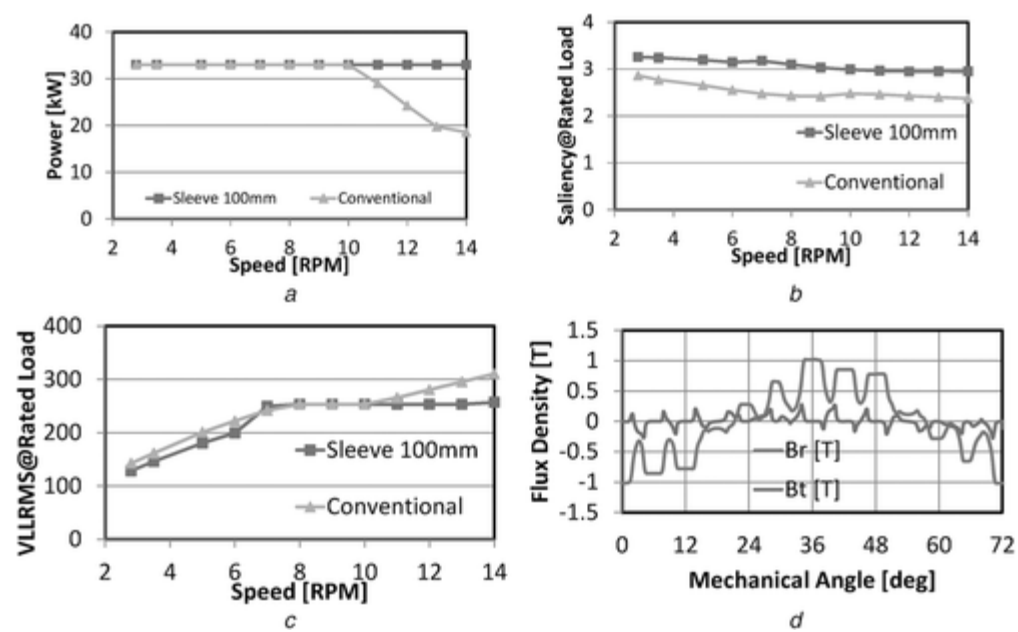

Fig. 6 Rated output shaft power vs. speed for both motors $a$ Rated Power vs. Speed for the $100 \mathrm{~mm}$ sleeve design along with the conventional SynRel designs $b$ Saliency at Rated Power vs. Speed for the $100 \mathrm{~mm}$ sleeve design along with the conventional SynRel design $c$ Vllrms at Rated Power vs. Speed for the two sleeve designs along with the conventional SynRel design $d$ Radial and Tangential Air-gap Flux Density Harmonics at the peak torque excitation in the Conventional SynRel Design

The air-gap flux density in the conventional SR design under the peak torque conditions (i.e. an excitation of $400 \mathrm{Arms}, 50^{\circ} \mathrm{gamma}$ ) is shown in Fig. $\mathbf{6 d}$. Peak values of the Fourier harmonic components of the radial and tangential flux densities under the peak torque condition are shown in 
Fig. 7a. The 11th harmonic in this design exceeds a flux density of $0.2 \mathrm{~T}$, and will have a significant impact on the rotor losses, and torque ripple of the machine. Various losses in the machine are estimated with the help of analytical as well as finite element tools. The copper loss calculations use a factor of $10 \%$ to account for the AC loss effects (for litz winding), with a copper fill factor of $40 \%$ in the machine. The iron loss in the stator and rotor are calculated in the finite element program. For the sake of comparisons, only electromagnetic efficiency is compared is and the friction and windage losses are not included in the final comparisons. Efficiency in both designs is seen to be low, around $85 \%$ in the lower speed regions. This is due to the copper losses being quite significant at the lower speeds, which reduces the efficiency. At higher speeds, due to the reduction of torque requirement, the current reduces and the efficiency improves.
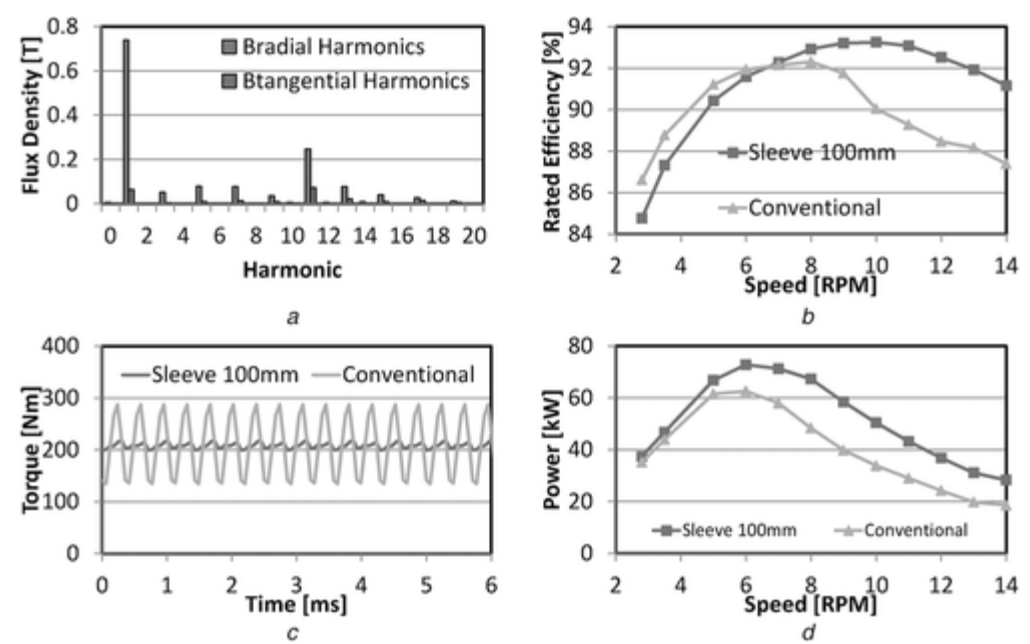

Fig. 7 Peak values of the Fourier harmonic components of the radial and tangential flux densities under the peak torque condition

$a$ Radial and tangential air-gap flux density harmonics under the peak torque excitation conventional SynRel design

$b$ Efficiency at rated power vs. speed for the two sleeve designs along with the conventional SynRel design $c$ Peak Torque vs. time, showing the torque ripple for the three motors, scaled to the same average torque of $208 \mathrm{Nm}$

$d$ Power capability vs. speed under 300 Arms for sleeve and conventional SR motors

The variation of efficiency under rated load conditions of the designs is shown in Fig. $7 \mathbf{b}$. Both designs are quite similar in terms of efficiency up to the speed of $7000 \mathrm{rpm}$. At higher speeds, the current requirement of the conventional SynRel design increases to the point where the design can no longer meet the power requirements within the voltage constraint. This leads to the sleeve SynRel design having a better efficiency than the conventional SynRel machine above $7000 \mathrm{rpm}$.

The comparison of the rotor losses is important from the perspective of cooling. Even though the rotor does not contain any material susceptible to low temperature limits, the losses are important from the perspective of heat flow to the shaft and the bearings as well as thermal expansion of the rotor into the air-gap. In the conventional rotor design, rotor losses are within $400 \mathrm{~W}$ for the entire speed regime. The sleeve rotor designs are able to cut down these losses by nearly a factor of three. This is due to larger electromagnetic air-gap, where the air-gap harmonics are lower and is highly effective in limiting the thermal growth as well as lower rotor temperatures. The comparison of torque ripple at peak 
power Fig. 7c shows that the torque ripple is significantly reduced in the sleeve designs. The sleeve design at $100 \mathrm{~mm}$ has a torque ripple of just $9.5 \%$. This is a significant reduction as compared to the conventional design having a torque ripple of $72.8 \%$ at the peak power operating condition. The reduction of torque ripple in the sleeve designs attributes to the reduced harmonic content in the sleeve rotor as compared to the conventional designs, mainly due to the larger effective air gap.

The comparison of the motor power capabilities with a current of 300 Arms and 325 VDC is shown in Fig. 7d. All the sleeve designs perform in a similar manner in terms of the power capability at the low speeds up to $3000 \mathrm{rpm}$. At speeds above $3000 \mathrm{rpm}$, the sleeve SynRel design gains advantage over the conventional SynRel design and is $16 \%$ better in terms of the maximum power capability. At a speed of $6000 \mathrm{rpm}$ and within the voltage limits of 325 VDC, the sleeve design with $100 \mathrm{~mm}$ air-gap radius is able to produce an output power of $72.8 \mathrm{~kW}$. In addition, it can be seen that the sleeve SynRel design is able to provide the specified power up to the speed of $14,000 \mathrm{rpm}$, while the conventional SynRel design is unable to meet the power beyond a speed of $10,000 \mathrm{rpm}$.

\section{Conclusions}

A novel method of designing a SynRel machine with a rotor sleeve is presented in this paper. The introduction of the rotor sleeve is seen to allow the SynRel design to operate at a higher rotor radius/tip speed. The higher air-gap radius allows for better saliency compared with a conventional SynRel design with bridges, helping the design to achieve a wider constant power to speed ratio, besides also reducing the rotor losses and torque ripple. The mechanical analysis behind the sleeve stresses shows that the sleeve design is feasible up to the top speed of $14,000 \mathrm{rpm}$. The final sleeve SynRel motor is seen to be superior to the conventional SynRel motor in terms of power density, efficiency, flux-weakening, power capability, torque ripple and rotor losses.

\section{Acknowledgment}

This work has been supported in part by US Department of Energy grant no. DE-E0005573.

\section{References}

1 Miller, T.J.E., Hutton, A., Cossar, C., et al: 'Design of a synchronous reluctance motor drive', IEEE Trans. Ind. Appl., 1991, 27, (4), pp. 741- 749 (doi: https://doi.org/10.1109/28.85491)

2 Vagati, A., Franceschini, G., Marongiu, I., et al: ' Design criteria of high performance synchronous reluctance motors'. Industry Applications Society Annual Meeting, 1992, Conf. Record of the 1992 IEEE, 4-9 October 1992, vol. 1, pp. 66-73

3 Fratta, A., Troglia, G.P., Vagati, A., et al: ' Evaluation of torque ripple in high performance synchronous reluctance machines'. Industry Applications Society Annual Meeting, 1993, Conf. Record of the 1993 IEEE, 2-8 October 1993, vol. 1, pp. 163- 170

4 Matsuo, T., Lipo, T.A.: 'Rotor design optimization of synchronous reluctance machine', IEEE Trans. Energy Convers., 1994, 9, (2), pp. 359- 365 (doi: https://doi.org/10.1109/60.300136)

5 Vagati, A.: ' The synchronous reluctance solution: a new alternative in AC drives'. 20th Int. Conf. on Industrial Electronics, Control and Instrumentation, 1994. IECON '94, 5-9 September 1994, vol. 1, pp. 1- 13 
6 Staton, D.A., Soong, W.L., Miller, T.J.E.: 'Unified theory of torque production in switched reluctance and synchronous reluctance motors', IEEE Trans. Ind. Appl., 1995, 31, (2), pp. 329- 337 (doi: https://doi.org/10.1109/28.370281)

$7 \mathrm{Xu}, \mathrm{L} ., \mathrm{Xu}, \mathrm{X}$. , Lipo, T.A., et al: 'Vector control of a synchronous reluctance motor including saturation and iron loss', IEEE Trans. Ind. Appl., 1991, 27, (5), pp. 977- 985 (doi: https://doi.org/10.1109/28.90356)

8 Betz, R.E.: 'Theoretical aspects of control of synchronous reluctance machines', IEE Proc. B Electr. Power Appl., 1992, 139, (4), pp. 355- 364 (doi: https://doi.org/10.1049/ip-b.1992.0042)

9 Lagerquist, R., Boldea, I., Miller, T.J.E.: 'Sensorless-control of the synchronous reluctance motor', IEEE Trans. Ind. Appl., 1994, 30, (3), pp. 673-682 (doi: https://doi.org/10.1109/28.293716)

10 Soong, W.L., Miller, T.J.E.: ' Theoretical limitations to the field-weakening performance of the five classes of brushless synchronous AC motor drive'. Sixth Int. Conf. on Electrical Machines and Drives, 1993 (Conf. Publ. No. 376), 8-10 September 1993, pp. 127- 132

11 Fang, L., Lee, B.H., Lee, J.J., et al: ' Study on high-efficiency characteristics of interior permanent magnet synchronous motor with different magnet material'. Int. Conf. on Electrical Machines and Systems, 2009. ICEMS 2009. 15-18 November 2009, pp. 1-4

12 Sekerak, P., Hrabovcova, V., Pyrhonen, J., et al: 'Comparison of synchronous motors with different permanent magnet and winding types', IEEE Trans. Magn., 2013, 49, (3), pp. 1256- 1263 (doi: https://doi.org/10.1109/TMAG.2012.2230334)

13 Vartanian, R., Deshpande, Y., Toliyat, H.A.: ' Performance analysis of a rare earth magnet based NEMA frame permanent magnet assisted synchronous reluctance machine with different magnet type and quantity'. 2013 IEEE Int. Electric Machines and Drives Conf. (IEMDC), 12-15 May 2013, pp. 476- 483

14 El-Refaie, A.M., Alexander, J.P., Galioto, S., et al: ' Advanced high power-density interior permanent magnet motor for traction applications'. 2013 IEEE Energy Conversion Congress and Exposition (ECCE), 15-19 September 2013, pp. 581- 590 